Buana Sains Vol 18 No 1: 73 - 84, 2018

\title{
ANALISIS POTENSI DAN STRATEGI PENGEMBANGAN AGROWISATA (Studi Kasus di Study Wisata Bukit Flora, Desa Gunung Petung, Nongkojajar, Kecamatan Tutur, Kabupaten Pasuruan)
}

\author{
A. Yusuf Kholil dan Farah Mutiara \\ Program Studi Agribisnis, Fakultas Pertanian, Universitas Tribhuwana Tunggadewi
}

\begin{abstract}
The first purpose of the research were to identify and analyze potential of agrotourism Bukit Flora and potential area to support development agrotourism Bukit Flora. The second purpose is to identify and analize internal and external environment agrotourism Bukit Flora the factors into strengths, weaknesses, oppurtunities and threats for development agrotourism of Bukit Flora and the last purpose in this research is formulate appropriate strategies for development strategy of agrotourism Bukit Flora.Data analysis method use descriptive analysis and qualitative analysis. Descriptive analysis was used to analyze the potential of agrotourism Bukit Flora and identify the main factors to give weight to the factors that we have setconsisting of strengths, opportunities, weaknesses and threats by comparing the rows and columns of each variable on internal factors (IFE) and external (EFE). While the use of qualitative analysis in the form of a SWOT analysis and SWOT matrix IE matrix is used to analyze the development of agrotourism strategy using analysisQSPM.IFE total weighted scores of 2.56 and 2.30 for EFE. Placing agro Bukit Flora is in cell V. Based on the results of the SWOT matrix analysis, it can be obtained by four alternative strategies that can be taken in the development of agro Bukit Flora. Based on the results QSPM matrix, the value of the attraction was highest at 3 strategy with the total amount of the appeal (TAS) was 6.26.
\end{abstract}

Keywords : Internal Factors Evaluation (IFE); Eksternal Factors Evaluation (EFE), SWOT Matrix; QSPM Matrix.

\section{Pendahuluan}

Sektor Pariwisata merupakan sektor penting dalam upaya penerimaan Pendapatan Asli Daerah (PAD) yang cukup potensial. Hal ini akan lebih maksimal jika didukung oleh obyek yang ditawarkan menarik, kemudahan akses serta promosi yang baik. Adanya dukungan tersebut akan lebih meningkatkan pertumbuhan sektor pariwisata secara tidak langsung akan meningkatkan pendapatan masyarakat sekitar dan Pendapatan Asli Daerah (PAD) Kabupaten yang bersangkutan.
Salah satu sektor pariwisata di Indonesia yang potensial untuk dikembangkan adalah agrowisata. Agrowisata merupakan diversifikasi produk wisata yang menggabungkan aktivitas pertanian (agro) dan rekreasi di sebuah lingkungan pertanian. Agrowisata (agrotourism) merupakan salah satu istilah yang digunakan untuk mendeskripsikan wisata di pedesaan (rural tourism), selain farm tourism, soft tourism dan ecotourism (Suyitno, 2001). Konsep agrowisata sekaligus menjadi daya tarik wisata adalah terdapat something to see (ada sesuatu yang bisa dilihat), something to do (ada sesuatu yang 
A. Y. Kholil dan F. Muiara/ Buana Sains Vol 18 No $1: 73-84$

bisa dilakukan) dan something to buy (ada sesuatu yang bisa dibeli) (Karyono, 1997). Didalam agrowisata terdapat pemandangan atau keindahan alam pertanian yang dapat dilihat (something to see).

Terdapat beberapa jenis agrowisata yang dapat diidentifikasikan berdasarkan potensi komoditas dan lingkungannya. Obyek pertanian yang dikemas dan ditawarkan sebagai produk agrowisata sangat banyak dan bervariasi yang menawarkan keindahan alam serta lokasi pengolahan dimana pengunjung dapat melihat proses produksinya seperti halnya di daerah Nongkojajar. Agrowisata Bukit Flora yang terletak di Desa Gunung Petung, Nongkojajar, Kecamatan Tutur, Kabupaten Pasuruan merupakan agrowisata yang menawarkan tanaman hias dan tanaman obat sebagai obyek wisatanya. Melalui agrowisata Bukit Flora pengunjung dapat mempelajari jenis-jenis tanaman hias dan tanaman obat di kebun pembibitan dengan lingkungan taman dan kebun koleksi dengan lingkungan hutan.

Sebagai salah satu unit usaha, agrowisata Bukit Flora masih menghadapi berbagai kendala dalam pengembangan usaha. Sejak berdiri tahun 2007, usaha ini masih menghadapi kendala baik internal maupun eksternal dalam proses perkembangan usahanya. Adanya kondisi demikian maka diperlukan suatu penelitian mengenai perumusan strategi pengembangan yang tepat untuk perkembangan usaha agrowisata di masa mendatang. Hal ini dapat dilakukan dengan mengidentifikasi potensi agrowisata dan faktor-faktor penyebab agrowisata kurang berkembang. Kemudian menganalisis faktor-faktor tersebut ke dalam faktor internal dan eksternal yang ada didalam agrowisata Bukit Flora. Dari faktor internal dan eksternal dapat dirumuskan strategi pengembangan yang tepat. Strategi yang tepat ini diharapkan dapat menunjang agrowisata Bukit Floradalam meningkatkan usahanya. Kemudian kedepannya mampu mendorong petani dan masyarakat sekitar untuk ikut berperan demi kemajuan usahanya dan pertanian pada umumnya. Maka dari itu, perlu dilakukan analisis potensi dan strategi pengembangan agrowisata Bukit Flora.

\section{Metode Penelitian}

Penentuan lokasi penelitian dilakukan secara sengaja (purposive) yaitu agrowisata Bukit Flora dengan pertimbangan bahwa agrowisata Bukit Flora merupakan usaha agrowisata yang dikemas dengan study wisatayang didalamnya melakukan pembudidayaan tanaman hias dan tanaman obat yang terbilang baru (pionir) dalam bisnis agrowisata yang memungkinkan ketersediaan data untuk keperluan penelitian ini. Penelitian ini dilakukan pada bulan November 2013.

\section{Metode Penentuan Responden}

Metode penentuan responden dalam penelitian termasuk dalam nonprobability sampling karena tidak memberi kemungkinan yang sama bagi tiap unsur populasi untuk dipilih. Dalam penelitian ini, peneliti menggunakan teknik critical case sampling untuk responden faktor internal dan teknik accidental sampling untuk responden faktor eksternal.

1. Teknik Critical Case Sampling

Peneliti menggunakan teknik inidengan pertimbangan bahwa responden harus memiliki tingkat penguasaan yang tinggi terhadap bidang yang akan diteliti sekaligus permasalahannya. Jumlah responden yang diambil berjumlah 4 orang responden. Responden terdiri dari 
A. Y. Kholil dan F. Muiara/ Buana Sains Vol 18 No 1 : 73-84

Pemilik agrowisata dan Pengelola agrowisata Bukit Flora dengan proses dialog atau wawancara untuk memperoleh informasi faktor internal agrowisata Bukit Flora.

\section{Teknik Accidental Sampling}

Dalam penelitian ini, populasinya adalah pengunjung agrowisata Bukit Flora dengan jumlah yang tidak diketahui secara pasti. Tidak diketahui secara pasti karena pengunjung yang datang setiap hari berbeda jumlahnya sehingga tidak bisa diprediksikan berapa orang yang akan berkunjung. Teknik pengambilan sampel yang diambil berdasarkan pertimbangan bahwa populasi yang ada tidak diketahui secara pasti jumlahnya sehingga menggunakan Accidental Sampling yaitu pengambilan sampel yang dilakukan kepada siapa saja yang kebetulan ada (Soeratno dan Lincolin,2008). Dalam hal ini responden ditujukan kepada pengunjung agrowisata. Jumlah responden yang diambil sebanyak 25 orang responden atau pengunjung dengan pemberian kuisioner untuk memperoleh informasi faktor eksternal agrowisata Bukit Fora.

\section{Metode Pengumpulan Data}

Metode pengumpulan data yang akan digunakan dalam penelitian ini adalah:

\section{Data Primer}

a. Wawancara dengan menggunakan daftar pertanyaan atau kuisioner meliputi keadaan lingkungan internal dan eksternal agrowisata Bukit Flora diantaranya mengenai kunjungan, struktur organisasi, sejarah dan lain-lain serta pengamatan langsung di lapangan. Narasumber utama dalam eksplorasi data primer dalam penelitian adalah pemilik Agrowisata Bukit Flora, para pengelola agrowisata dan pegunjung agrowisata Bukit Flora. b. Observasi untuk meneliti beberapa segi dari masalah yang dijadikan sasaran untuk memperoleh fakta-fakta yang diperlukan. Dalam penelitian ini observasi dipakai untuk mengamati situasi yang terkit dengan potensi daerah di sekitar lingkungan internal dan eksternal agrowisata Bukit Flora dalam menentukan strategi usaha.

c. Dokumentasi yaitu suatu teknik pengumpulan data yang dibutuhkan apabila data tersebut tersedia dalam bentuk tertulis. Metode ini digunakan untuk memperoleh data primer tentang gambaran umum dari agrowisata Bukit Flora.

2. Data Sekunder

Digunakan untuk melengkapi bahan-bahan dan informasi yang didapat selama melakukan penelitian, yaitu yang berasal dari literatur atau pustaka.Data yang didapat dari studi literatur ini berupa data sekunder, yaitu data yang didapat bukan dari sumber-sumber asli.Data juga bisa didapat dari dokumen atau arsip terkait atau bahkan penelitian terdahulu.

\section{Metode Analisis Data}

Metode analisis data yang digunakan yaitu analisis deskriptif dan analisis kualitatif. Analisis deskriptif digunakan untuk menganalisis potensi agrowisata Bukit Flora dan mengidentifikasi faktor utama untuk memberikan bobot pada faktor yang sudah kita tentukan terdiri dari kekuatan, peluang, kelemahan dan ancaman dengan membandingkan antara baris dan kolom dari masing-masing variabel pada faktor internal (IFE) dan eksternal (EFE). Sedangkan dalam analisis kualitatif menggunakan analisis SWOT yang berupa matriks IE dan matriks SWOT yang digunakan untuk menganalisis strategi pengembangan agrowisata Bukit Flora menggunakan analisis QSPM. 
A. Y. Kholil dan F. Muiara/ Buana Sains Vol 18 No $1: 73-84$

\section{Hasil dan Pembahasan}

Pada bagian ini akan dilakukan analisis data mengenai Strategi Pengembangan Agrowisata Bukit Flora. Berdasarkan hasil analisis tersebut maka dapat diuraikan sebagai berikut:

Analisis Potensi

Potensi agrowisata Bukit Flora terdiri dari sesuatu yang dapat dilihat (something to see), sesuatu yang dapat dilakukan (something to do) dan sesuatu yang dapat dibeli (something to buy).

\section{a. Something to see}

Suasana daerah di sekitar agrowisata Bukit Flora yakni Desa Gunung Petung, Nongkojajarmasih kental dengan suasana pedesaan dan kondisi lingkunganyang masih alami. Hal ini menjadi sesuatu yang dapat dilihat oleh pengunjung yang datang. Setelah masuk ke dalam agrowisata, pengunjung langsung dimanjakan dengan kebun greenhouse tanaman hias dan tanaman obat serta kebun wisata outbond yang dilengkapi dengan kolam renang fasilitas waterboom.

\section{b. Something to do}

Di agrowisata Bukit Flora, pengunjung dapat melakukan banyak kegiatan wisata.Objek wisatanya pun beragam dan dapat dilakukan baik untuk individu maupun rombongan. Kegiatan yang dapat dilakukan diantaranya wisata edukasi dengan mengenal dan mempelajari tanaman hias dan tanaman obat, seperti mengenal macam-macam tanaman hias, cara bercocok tanam, manfaat tanaman obat dan sebagianya. Selain itu, pengunjung dapat melakukan wisata yang lain seperti berenang, flying fox, outbond dan berkemah.

\section{c. Something to buy}

Cinderamata atau oleh-oleh penting bagi pengunjung sebagai buah tangan untuk keluarga di rumah. Di agrowisata Bukit Floraterdapat produk yang dapat dibeli pengunjung sebagai oleh-oleh seperti, produk tanaman hias dan tanaman obat, souvenir, kaos dan sebagainya.

\section{Analisis IFE dan EFE}

Matriks IFE (Internal Factors Evaluation) dilakukan dengan menentukan total skor pada analisis lingkungan internal. Penentuan skor pada analisis lingkungan internal diperoleh dari hasil perkalian antara bobot dan rating. Nilai rating ditentukan berdasarkan seberapa besar pengaruh faktor-faktor internal terhadap agrowisata Bukit Flora. Adapun hasil matriks IFE (Internal Factors Evaluation) dapat dilihat pada tabel 1.

Berdasarkan hasil perhitungan matriks IFE (Internal Factors Evaluation) (Internal Factors Evaluation), faktor strategis yang menjadi kekuatan terbesar dan paling berpengaruh bagi agrowisata Bukit Flora adalah rekreasi yang ditawarkan adalah rekreasi edukatif dimana dalam agrowisata Bukit Flora sebagai tempat rekreasi yang menawarkan rekreasi edukatif yaitu dengan mempelajari dan mengenali macam-macam tanaman hias dan tanaman obat dengan skor sebesar 0,56. Sedangkan faktor strategis internal yang menjadi kelemahan terbesar dan paling berpengaruh bagi agrowisata Bukit Flora adalah permodalan dari dana pribadi dengan skor sebesar 0,22. Hal ini dikarenakan usaha agrowisata Bukit Flora merupakan usaha keluarga yang didirikan sendiri dan dibiayai sendiri seluruh kebutuhannya oleh Bapak H.Abdul Qodir. Hasil analisis matriks IFE (Internal Factors Evaluation) untuk kekuatan dan kelemahan diperoleh total skor faktor internal sebesar 2,56. Hal ini menunjukkan bahwa kemampuan agrowisata Bukit Flora dalam hal mengatasi kelemahan dengan menggunakan kekuatan berada pada posisi rata-rata. 
A. Y. Kholil dan F. Muiara/ Buana Sains Vol 18 No 1 : 73-84

Tabel 1. Matriks IFE (Internal Factors Evaluation)

\begin{tabular}{|c|c|c|c|c|}
\hline No. & Faktor Internal Kunci & Bobot & Rating & Skor Bobot \\
\hline & Kekuatan (S) & (Ai) & $(\mathrm{Bi})=1,2,3,4$ & $(\mathrm{Ai} \times \mathrm{Bi})$ \\
\hline A. & $\begin{array}{l}\text { Agrowisata yang baru (pionir) } \\
\text { dalam wisata tanaman hias dan } \\
\text { tanaman obat }\end{array}$ & 0,07 & 2 & 0,14 \\
\hline B. & $\begin{array}{l}\text { Rekreasi yang ditawarkan } \\
\text { adalah rekresi edukatif }\end{array}$ & 0,14 & 4 & 0,56 \\
\hline C. & $\begin{array}{l}\text { Udara yang sejuk dan } \\
\text { pemandangan yang indah }\end{array}$ & 0,07 & 2 & 0,14 \\
\hline D. & $\begin{array}{l}\text { Harga paket agrowisata yang } \\
\text { ditawarkan murah }\end{array}$ & 0,12 & 3 & 0,36 \\
\hline E. & $\begin{array}{l}\text { Adanya paket agrowisata } \\
\text { outbond yang menarik }\end{array}$ & 0,06 & 3 & 0,18 \\
\hline F. & $\begin{array}{l}\text { Menawarkan produk wisata } \\
\text { yang berbeda dengan jenis } \\
\text { wisata yang sudah ada }\end{array}$ & 0,05 & 3 & 0,15 \\
\hline G. & $\begin{array}{l}\text { Tersedianya fasilitas waterboom } \\
\text { dikolam renang }\end{array}$ & 0,08 & 3 & 0,24 \\
\hline \multicolumn{2}{|r|}{ Total Skor Kekuatan } & 0,59 & 20 & 1,77 \\
\hline & Kelemahan (W) & & & \\
\hline \multirow{6}{*}{$\begin{array}{l}\text { H. } \\
\text { I. } \\
\text { J. } \\
\text { K. } \\
\text { L. } \\
\text { M. }\end{array}$} & \multirow{6}{*}{$\begin{array}{l}\text { Promosi yang masih belum } \\
\text { intensif } \\
\text { Keadaan kebun yang belum } \\
\text { tertata } \\
\text { Permodalan dari dana pribadi } \\
\text { Belum tersedianya tenaga } \\
\text { administrasi } \\
\text { Lokasi yang jauh dari pusat } \\
\text { kota } \\
\text { Pelayananan agrowisata yang } \\
\text { kurang memuaskan }\end{array}$} & 0,09 & 1 & 0,09 \\
\hline & & 0,04 & 3 & 0,12 \\
\hline & & 0,11 & 2 & 0,22 \\
\hline & & 0,08 & 2 & 0,16 \\
\hline & & 0,01 & 4 & 0,04 \\
\hline & & 0,08 & 2 & 0,16 \\
\hline \multicolumn{2}{|r|}{ Total Skor Kelemahan } & 0,41 & 14 & 0,79 \\
\hline \multicolumn{2}{|r|}{ Total Skor Faktor Internal } & 1,0 & 34 & 2,56 \\
\hline
\end{tabular}

Sumber: Data Primer Diolah, 2014.

Matriks EFE (External Factors Evaluation) dapat dilakukan dengan menentukan total skor pada analisis lingkungan eksternal. Penentuan skor pada analisis lingkungan eksternal diperoleh dari hasil perkalian antara bobot dan rating. Nilai rating ditentukan berdasarkan seberapa besar pengaruh faktor-faktor eksternal terhadap agrowisata Bukit Flora. Adapun hasil matriks EFE (External Factors Evaluation) dapat dilihat pada tabel 2. 
Tabel 2. Matriks EFE (External Factors Evaluation)

\begin{tabular}{|c|c|c|c|c|}
\hline No. & Faktor Eksternal Kunci & Bobot & Rating & Skor Bobot \\
\hline & Peluang (O) & (Ai) & $(B i)=1,2,3,4$ & $(\mathrm{Ai} \times \mathrm{Bi})$ \\
\hline A. & $\begin{array}{l}\text { Pesaing yang menawarkan } \\
\text { obyek wisata yang sama dalam } \\
\text { satu daerah belum ada }\end{array}$ & 0,10 & 3 & 0,30 \\
\hline B. & $\begin{array}{lcr}\begin{array}{l}\text { Selera } \\
\text { berwisata }\end{array} & \text { yang } & \text { dalam } \\
\text { berbasis }\end{array}$ & 0,10 & 3 & 0,30 \\
\hline C. & $\begin{array}{l}\text { lingkungan } \\
\text { Trend masvarakat kembali ke }\end{array}$ & 0,15 & 4 & 0,60 \\
\hline D. & $\begin{array}{l}\text { lrend masyarakat kemball ke } \\
\text { alam (back to nature) } \\
\text { Tawaran dari lembaga }\end{array}$ & 0,10 & 2 & 0,20 \\
\hline E. & $\begin{array}{l}\text { keuangan } \\
\text { Wisata sebagai bagian dari } \\
\text { kebutuhan }\end{array}$ & 0,05 & 2 & 0,10 \\
\hline & Total Skor Peluang & 0,50 & 14 & 1,50 \\
\hline & Ancaman (T) & & & \\
\hline $\mathrm{F}$. & $\begin{array}{l}\text { Masih Kurangnya dukungan } \\
\text { pemerintah daerah setempat }\end{array}$ & 010 & 2 & 0,20 \\
\hline G. & Akan tumbuh agrowisata lain & 0,20 & 2 & 0,40 \\
\hline H. & $\begin{array}{l}\text { Pengunjung memilih obyek } \\
\text { wisata yang lain }\end{array}$ & 0,10 & 1 & 0,10 \\
\hline I. & $\begin{array}{l}\text { Pengunjung tidak } \\
\text { merekomendasikan ke orang } \\
\text { lain. }\end{array}$ & 0,10 & 1 & 0,10 \\
\hline & Total Skor Ancaman & 0,50 & 6 & 0,80 \\
\hline \multicolumn{2}{|r|}{ Total Skor Faktor Eksternal } & 1,00 & 20 & 2,30 \\
\hline
\end{tabular}

Sumber: Data Primer Diolah, 2014.

Berdasarkan hasil perhitungan matriks EFE (External Factors Evaluation), faktor eksternal yang menjadi peluang terbesar bagi agrowisata Bukit Flora adalah trend masyarakat untuk kembali ke alam (back to nature) dengan skor sebesar 0,60. Karena, agrowisata sebagai rekreasi yang berwawasan lingkungan pertanian maka dengan trend masyarakat untuk kembali ke alam maka agrowisata akan menjadi sangat ramai untuk dikunjungi. Sedangkan faktor eksternal yang menjadi ancaman terbesar bagi agrowisata Bukit Flora adalah akan tumbuh agrowisata lain dengan skor sebesar 0,40. Hasil analisis matriks EFE untuk peluang dan ancaman diperoleh total skor faktor eksternal sebesar 2,30. Hal ini menunjukkan bahwa kemampuan agrowisata Bukit Flora dalam merespon peluang untuk menghindari ancaman tergolong rata-rata.

\section{Analisis Matriks Internal - Eksternal (IE) \\ Untuk mempermudah dalam} memberikan pemilihan alternatif strategi, maka dibuat matriks internal-eksternal (IE). Karena dari matriks I-E dapat diketahui posisi perusahaan saat ini. Gambar analisis matriks internaleksternal (I-E) dapat dilihat pada gambar. 1. 


\section{Gambar 1. Matriks Internal-Eksternal}

Berdasarkan hasil yang diperoleh dari matriks IFE dan matriks EFE, maka dapat disusun matriks I-E. Total skor bobot IFE sebesar 2,56 dan EFE sebesar 2,30. Menempatkan agrowisata Bukit Flora berada pada sel V. Posisi ini menggambarkan agrowisata Bukit Flora dalam kondisi internal rata-rata dan respon perusahaan terhadap faktorfaktor eksternal yang dihadapinya tergolong sedang. Strategi yang dapat dilaksanakan adalah growth and stability atau strategi pertumbuhan dan stabilitas yang terdapat pada agrowisata Bukit Flora .

\section{Analisis Matriks SWOT}

Berbagai alternatif strategi dapat dirumuskan berdasarkan analisis matriks SWOT (Strength, Weakness, Opportunities, Threath). Keunggulan dari matriks ini adalah mempermudah untuk memformulasikan strategi berdasarkan gabungan faktor internal dan eksternal. Empat strategi utama yang disarankan yaitu SO, WO, ST dan WT. Analisis ini menggunakan data yang telah diperoleh matriks IFE (Internal Factors Evaluation) dan EFE (External Factors Evaluation) sebelumnya. Hasil matriks analisis SWOT (Strength, Weakness, Opportunities, Threath) dapat dilihat pada tabel. 
Tabel 3. Matriks SWOT pada Agrowisata Bukit Flora

\begin{tabular}{|c|c|c|}
\hline IFE & Kekuatan (S) & Kelemahan (W) \\
\hline EFE & $\begin{array}{l}\text { 1. Agrowisata yang baru (pionir) } \\
\text { dalam wisata kebun tanaman hias } \\
\text { dan tanaman obat } \\
\text { 2. Rekreasi yang ditawarkan adalah } \\
\text { rekreasi edukatif } \\
\text { 3. Udara yang sejuk dan } \\
\text { pemandangan yang indah } \\
\text { 4. Harga paket agrowisata yang } \\
\text { ditawarkan murah } \\
\text { 5. Adanya paket agrowisata outbond } \\
\text { yang menarik } \\
\text { 6. Menawarkan produk wisata yang } \\
\text { berbeda dengan jenis wisata yang } \\
\text { sudah ada } \\
\text { 7. Tersedianya fasilitas waterboom di } \\
\text { kolam renang }\end{array}$ & $\begin{array}{l}\text { a. Promosi yang masih belum } \\
\text { intensif } \\
\text { b. Keadaan kebun yang belum } \\
\text { tertata } \\
\text { c. Permodalan dari dana pribadi } \\
\text { d. Belum tersedianya tenaga } \\
\text { administrasi } \\
\text { e. Lokasi yang jauh dari pusat kota } \\
\text { f. Pelayanan agrowisata yang } \\
\text { kurang memuaskan }\end{array}$ \\
\hline $\begin{array}{l}\text { Peluang (O) } \\
\text { 1. Pesaing yang } \\
\text { menawarkan obyek } \\
\text { wisata yang sama } \\
\text { dalam satu daerah } \\
\text { belum ada } \\
\text { 2. Selera pengunjung } \\
\text { dalam berwisata } \\
\text { yang berbasis } \\
\text { lingkungan } \\
\text { 3rend masyarakat } \\
\text { kembali ke alam } \\
\text { (back to nature) } \\
\text { 4awaran dari } \\
\text { lembaga keuangan } \\
\text { Wisata sebagai } \\
\text { bagian dari } \\
\text { kebutuhan }\end{array}$ & $\begin{array}{l}\text { Strategi SO } \\
\text { 1. Menciptakan dan } \\
\text { mengorientasikan agrowisata Bukit } \\
\text { Flora sebagai agrowisata yang baru } \\
\text { dengan mengoptimalkan potensi } \\
\text { dan keunggulan yang dimiliki. S1, } \\
\text { S2, S6, O1, O2, O3. } \\
\text { 2. Memanfaatkan selera wisata yang } \\
\text { berbasis lingkungan dengan } \\
\text { mengoptimalkan produk yng } \\
\text { bernuansa alam. S1, S3, S5, S6, } \\
\text { O2, O3, O4. }\end{array}$ & \begin{tabular}{ll} 
& \multicolumn{1}{c}{ Strategi WO } \\
a. & Meningkatkan kegiatan promosi \\
secara optimal dengan \\
memanfaatkan perkembangan \\
teknologi. W1, W6, O5. \\
b. Meningkatkan kualitas \\
Sumberdaya Manusia dengan \\
pelatihan untuk meningkatkan \\
kinerja serta mengaktifkan peran \\
litbang. W3, W4, W6, O4, O5. \\
c. Bekerjasama dengan instansi \\
terkait atau biro perjalanan \\
wisata. W6, O4, O5.
\end{tabular} \\
\hline $\begin{array}{l}\text { Ancaman (T) } \\
\text { 1. Masih kurangnya } \\
\text { dukungan } \\
\text { pemerntah daerah } \\
\text { setempat } \\
\text { 2. Akan tumbuh } \\
\text { agrowisata lain } \\
\text { 3. Pengunjung } \\
\text { memilih obyek } \\
\text { wisata yang lain } \\
\text { 4. Pengunjung tidak } \\
\text { merekomendasikan } \\
\text { kepada orang lain. }\end{array}$ & $\begin{array}{l}\text { Strategi ST } \\
\text { Menciptakan citra baik dimata } \\
\text { pengunjung untuk mengantisipasi } \\
\text { adanya pemilihan wisata lain. S2, } \\
\text { S4, S5, S6, S7, T2, T3, T4. } \\
\text { Memanfaatkan kualitas layanan } \\
\text { wisata dan mempertahankan } \\
\text { kualitas layanan wisata. S2, S4, S6, } \\
\text { S7, T1. }\end{array}$ & $\begin{array}{l}\text { Strategi WT } \\
\text { 1. } \\
\text { eningkatkan kualitas } \\
\text { sumberdaya manusia dan } \\
\text { manajemennya dengan } \\
\text { pelatihan khusus untuk } \\
\text { meningkatkan produktivtas } \\
\text { karyawan. W2, W4, W6, T3, } \\
\text { T4. } \\
\text { 2. } \\
\text { engikutsertakan agrowisata pada } \\
\text { pameran untuk } \\
\text { mempromosikan wisata agar } \\
\text { lebih dikenal. W1, W5, W6, T2, } \\
\text { T3, T4. }\end{array}$ \\
\hline
\end{tabular}

Sumber: Data Primer Diolah, 2014. 


\section{Analisis Matriks SWOT}

Berbagai alternatif strategi dapat dirumuskan berdasarkan analisis matriks SWOT (Strength, Weakness, Opportunities, Threath). Keunggulan dari matriks ini adalah mempermudah untuk memformulasikan strategi berdasarkan gabungan faktor internal dan eksternal. Empat strategi utama yang disarankan yaitu SO, WO, ST dan WT. Analisis ini menggunakan data yang telah diperoleh matriks IFE (Internal Factors Evaluation) dan EFE (External Factors Evaluation) sebelumnya. Hasil matriks analisis SWOT (Strength, Weakness, Opportunities, Threath) dapat dilihat pada tabel.

a. Strategi SO

Strategi SO yaitu strategi yang menggunakan kekuatan untuk memanfaatkan keuntungan dari peluang yang ada, terdiri dari:

1. Menciptakan dan mengorientasikan agrowisata Bukit Flora sebagai agrowisata yang baru dengan mengoptimalkan potensi dan keunggulan yang dimiliki (S1, S2, S6, $\mathrm{O} 1, \mathrm{O} 2, \mathrm{O} 3)$.

2. Memanfaatkan selera wisata yang berbasis lingkungan dengan mengoptimalkan produk yang bernuansa alam (S1, S3, S5, S6, O2, O3, O4).

b. Strategi WO

Strategi WO yaitu strategi yang memperkecil kelemahan dengan memanfaatkan keuntungan dari peluang yang ada, terdiri dari:

1. Meningkatkan kegiatan promosi secara optimal dengan memanfaatkan perkembangan teknologi (W1, W6, O5).

2. Meningkatkan kualitas Sumberdaya Manusia dengan pelatihan untuk meningkatkan kinerja serta mengaktifkan peran litbang (W3, W4, W6, O4, O5).
3. Bekerjasama dengan instansi terkait atau biro perjalanan wisata (W6, O4, O5).

c. Strategi ST

Strategi ST yaitu strategi menggunakan kekuatan untuk mengatasi ancaman, terdiri dari:

1. Menciptakan citra baik dimata pengunjung untuk mengantisipasi adanya pemilihan wisata lain $(\mathrm{S} 2, \mathrm{~S} 4$, S5, S6, S7, T2, T3, T4).

2. Memanfaatkan kualitas layanan wisata dan mempertahankan kualitas layanan wisata (S2, S4, S6, S7, T1).

d. Strategi WT

Strategi WT yaitu strategi meminimalkan kelemahan dan mengatasi ancaman, terdiri dari:

1. Meningkatkan kualitas sumberdaya manusia dan manajemennya dengan pelatihan khusus untuk meningkatkan produktivtas karyawan (W2, W4, W6, T3, T4).

2. Mengikutsertakan agrowisata pada pameran untuk mempromosikan wisata agar lebih dikenal (W1, W5, W6, T2, T3, T4).

\section{Analisis Matriks QSPM}

Matriks QSPM (Quantitative Strategy Plannig Matrix) adalah alat yang digunakan untuk mengevaluasi pilihan strategi alternatif secara obyektif berdasarkan faktor-faktor utama internal dan eksternal pada matriks IFE, Matriks EFE, matriks I-E (Internal - Eksternal) serta matriks SWOT. Penentuan alternatif strategi yang layak dimasukkan pada matriks QSPM (Quantitative Strategy) Plannig Matrix) berdasarkan penilaian atas kondisi perusahaan dan penggunaan intuisi. Matriks ini akan menentukan kemenarikan relatif (relative attractiveness) dari tindakan-tindakan strategi alternatif yang dapat dilaksanakan oleh agrowisata Bukit Flora. 
Tabel 4. Matriks QSPM pada Agrowisata Bukit Flora

\begin{tabular}{|c|c|c|c|c|c|c|c|c|c|c|}
\hline \multirow{2}{*}{ No } & \multirow{3}{*}{ Faktor Utama } & \multicolumn{9}{|c|}{ Alternatif Strategi } \\
\hline & & \multirow{2}{*}{ Bobot } & \multicolumn{2}{|c|}{ Strategi 1} & \multicolumn{2}{|c|}{ Strategi 2} & \multicolumn{2}{|c|}{ Strategi 3} & \multicolumn{2}{|c|}{ Strategi 4} \\
\hline Kekuatan (S) & & & $\overline{\text { AS }}$ & TAS & AS & TAS & AS & TAS & $\overline{\text { AS }}$ & TAS \\
\hline $\mathrm{A}$ & $\begin{array}{l}\text { Agrowisata yang baru (pionir) } \\
\text { dalam wisata kebun tanaman hias } \\
\text { dan tanaman obat }\end{array}$ & 0,07 & 4 & 0,28 & 3 & 0,21 & 3 & 0,21 & 3 & 0,21 \\
\hline B & $\begin{array}{l}\text { Rekreasi yang ditawarkan adalah } \\
\text { rekreasi edukatif }\end{array}$ & 0,14 & 4 & 0,56 & 3 & 0,42 & 4 & 0,56 & 3 & 0,42 \\
\hline $\mathrm{C}$ & $\begin{array}{l}\text { Udara yang sejuk dan } \\
\text { pemandangan yang indah }\end{array}$ & 0,07 & 3 & 0,21 & 2 & 0,14 & 3 & 0,21 & 1 & 0,07 \\
\hline $\mathrm{D}$ & $\begin{array}{l}\text { Harga paket agrowisata yang } \\
\text { ditawarkan murah }\end{array}$ & 0,12 & 3 & 0,36 & 2 & 0,24 & 4 & 0,48 & 2 & 0,24 \\
\hline $\mathrm{E}$ & $\begin{array}{l}\text { Adanya paket agrowisata outbond } \\
\text { yang menarik }\end{array}$ & 0,06 & 3 & 0,18 & 3 & 0,18 & 4 & 0,24 & 2 & 0,12 \\
\hline $\mathrm{F}$ & $\begin{array}{l}\text { Menawarkan produk wisata yang } \\
\text { berbeda dengan jenis wisata yang } \\
\text { sudah ada }\end{array}$ & 0,05 & 4 & 0,20 & 3 & 0,15 & 4 & 0,20 & 3 & 0,15 \\
\hline$G$ & $\begin{array}{l}\text { Tersedianya fasilitas wterboom di } \\
\text { kolam renang }\end{array}$ & 0,08 & 2 & 0,16 & 2 & 0,16 & 4 & 0,32 & 1 & 0,08 \\
\hline \multicolumn{11}{|c|}{ Kelemahan (W) } \\
\hline $\mathrm{H}$ & Promosi yang belum intensif & 0,09 & 3 & 0,27 & 4 & 0,36 & 3 & 0,27 & 4 & 0,36 \\
\hline I & Keadaan kebun yang belum tertata & 0,04 & 2 & 0,08 & 2 & 0,08 & 1 & 0,04 & 4 & 0,16 \\
\hline $\mathrm{J}$ & Permodalan dari dana pribadi & 0,11 & 2 & 0,22 & 4 & 0,44 & 2 & 0,22 & 4 & 0,44 \\
\hline $\mathrm{K}$ & $\begin{array}{l}\text { Belum tersedianya tenaga } \\
\text { administrasi }\end{array}$ & 0,08 & 2 & 0,16 & 4 & 0,32 & 2 & 0,16 & 3 & 0,24 \\
\hline $\mathrm{L}$ & Lokasi yang jauh dari pusat kota & 0,01 & 1 & 0,01 & 2 & 0,02 & 1 & 0,01 & 3 & 0,03 \\
\hline $\mathrm{M}$ & $\begin{array}{l}\text { Pelayanan agrowisata yang kurang } \\
\text { memuaskan }\end{array}$ & 0,08 & 3 & 0,24 & 4 & 0,32 & 3 & 0,24 & 4 & 0,32 \\
\hline \multicolumn{11}{|c|}{ Peluang $(\mathrm{O})$} \\
\hline A & $\begin{array}{l}\text { Pesaing yang menawarkan obyek } \\
\text { wisata yang sama dalam satu daerah } \\
\text { belum ada }\end{array}$ & 0,10 & 4 & 0,40 & 3 & 0,30 & 3 & 0,30 & 3 & 0,30 \\
\hline $\mathrm{B}$ & $\begin{array}{l}\text { Selera pengunjung dalam berwisata } \\
\text { yang berbasis lingkungan }\end{array}$ & 0,10 & 4 & 0,40 & 3 & 0,30 & 3 & 0,30 & 3 & 0,30 \\
\hline $\mathrm{C}$ & $\begin{array}{l}\text { Trend masyarakat kembali ke alam } \\
\text { (back to nature) }\end{array}$ & 0,15 & 4 & 0,60 & 3 & 0,45 & 3 & 0,45 & 3 & 0,45 \\
\hline $\mathrm{D}$ & Tawaran dari lembaga keuangan & 0,10 & 2 & 0,20 & 4 & 0,40 & 1 & 0,10 & 2 & 0,20 \\
\hline $\mathrm{E}$ & $\begin{array}{l}\text { Wisata sebagai bagian dari } \\
\text { kebutuhan }\end{array}$ & 0,05 & 2 & 0,10 & 4 & 0,20 & 1 & 0,05 & 3 & 0,15 \\
\hline \multicolumn{11}{|c|}{ Ancaman $(\mathrm{T})$} \\
\hline $\mathrm{F}$ & $\begin{array}{l}\text { Masih kurangnya dukungan } \\
\text { pemerintah daerah setempat }\end{array}$ & 0,10 & 3 & 0,30 & 2 & 0,20 & 3 & 0,30 & 3 & 0,30 \\
\hline G & Akan tumbuh agrowisata lain & 0,20 & 3 & 0,60 & 3 & 0,60 & 4 & 0,80 & 4 & 0,80 \\
\hline $\mathrm{H}$ & $\begin{array}{l}\text { Pengunjung memilih obyek wisata } \\
\text { yang lain }\end{array}$ & 0,10 & 3 & 0,30 & 3 & 0,30 & 4 & 0,40 & 4 & 0,40 \\
\hline $\mathrm{I}$ & $\begin{array}{l}\text { Pengunjung tidak } \\
\text { merekomendasikan ke orang lain }\end{array}$ & 0,10 & 2 & 0,20 & 1 & 0,10 & 4 & 0,40 & 4 & 0,40 \\
\hline & Total & & \multicolumn{2}{|c|}{6,03} & \multicolumn{2}{|c|}{5,89} & \multicolumn{2}{|c|}{$\frac{1}{6,26}$} & \multicolumn{2}{|c|}{6,14} \\
\hline
\end{tabular}

Sumber: Data Primer Diolah, 2014.

Berdasarkan hasil matriks QSPM, nilai daya tarik tertinggi terdapat pada strategi 3 dengan jumlah total daya tarik
(TAS) sebesar 6,26. Nilai daya tarik tertinggi kedua terdapat pada strategi 4 dengan jumlah TAS sebesar 6,14 dan 
tertinggi ketiga terdapat pada strategi 1 dengan total TAS sebesar 6,03. Sedangkan nilai daya tarik terendah terdapat pada strategi 2 dengan total TAS sebesar 5,89. Maka, strategi-strategi yang dapat didahulukan dalam penerapan strategi pengembangan agrowisata Bukit Flora dapat dirumuskan dengan urutan strategi sebagai berikut:

\section{Strategi ST}

a. Menciptakan citra baik dimata pengunjung untuk mengantisipasi adanya pemilihan wisata lain

b. Memanfaatkan kualitas layanan wisata dan mempertahankan kualitas layanan wisata

(Jumlah total daya tarik sebesar 6,26)

2. Strategi W'T sumberdaya manusia dan manajemennya dengan peltihan khusus untuk meningkatkan produktivitas karyawan
a. Meningkatkan kualitas
b. Mengikutsertakan agrowisata pada pameran untuk mempromosikan wisata agar lebih dikenal
(Jumlah total daya tarik sebesar 6,14)

3. Strategi SO

a. Menciptakan dan mengorientasikan agrowisata Bukit Flora sebagai agrowisata yang baru dengan mengoptimalkan potensi dan keunggulan yang dimiliki

b. Memanfaatkan selera wisata yang berbasis lingkungan dengan mengoptimalkan produk yang bernuansa alam (Jumlah total daya tarik sebesar 6,03)

\section{Strategi WO}
a. Meningkatkan kegiataan promosi secara optimal dengan memanfaatkan perkembangan teknologi
b. Meningkatkan kualitas sumberdaya manusia dengan

pelatihan untuk meningkatkan kinerja serta mengaktifkan peran litbang

c. Bekerjasama dengan instansi terkait atau biro perjalanan wisata (Total daya tarik sebesar 5,89)

\section{Kesimpulan}

Berdasarkan hasil penelitian dan pembahasan tentang analisis potensi dan strategi pengembangan agrowisata pada agrowisata Bukit Flora diperoleh beberapa kesimpulan sebagai berikut:

1. Hasil dari analisis potensi agrowisata Bukit Flora adalah agrowisata Bukit Flora berpotensi untuk dijadikan usaha agrowisata. Potensi agrowisata Bukit Flora terdiri dari sesuatu yang dapat dilihat (something to see), sesuatu yang dapat dilakukan (something to do) dan sesuatu yang dapat dibeli (sometbing to buy).

2. Analisis lingkungan yang dilakukan dalam agrowisata Bukit Flora ini adalah pada lingkungan internal dan eksternal agrowisata. Untuk lingkungan internal yang menjadi kekuatan pada agrowisata Bukit Flora adalah agrowisata Bukit Flora merupakan agrowisata yang baru (pionir) dalam wisata kebun tanaman hias dan tanaman obat, rekreasi yang ditawarkan adalah rekreasi edukatif, udara yang sejuk dan pemandangan yang indah, harga paket agrowisata yang ditawarkan murah, adanya paket agrowisata outbond yang menarik, menawarkan produk wisata yang berbeda dengan jenis wisata yang lain dan tersedianya fasilitas waterboom di kolam renang. Untuk lingkungan eksternal agrowisata yang menjadi peluang bagi agrowisata Bukit Flora adalah pesaing yang menawarkan obyek wisata yang sama dalam satu daerah belum ada, 
Selera pengunjung dalam berwisata yang berbasis lingkungan, trend masyarakat kembali ke alam (back to nature), tawaran dari lembaga keuangan, wisata sebagai bagian dari kebutuhan.

3. Dari hasil analisis yang digunakan untuk strategi pengembangan agrowisata pada agrowisata Bukit Flora, maka strategi-strategi yang seharusnya diterapkan berdasarkan hasil matriks SWOT dan matriks QSPM , nilai daya tarik tertinggi terdapat pada strategi 3 dengan jumlah total daya tarik (TAS) sebesar 6,26. Nilai daya tarik tertinggi kedua terdapat pada strategi 4 dengan jumlah TAS sebesar 6,14 dan tertinggi ketiga terdapat pada strategi 1 dengan total TAS sebesar 6,03.

\section{Daftar Pustaka}

Beeton T. 2006. Community Development through Tourism. Australia: Loudlink Press.

Brahmantyo, dkk . 2001. "Potensi dan Peluang Usaha dalam Pengembangan Pariwisata Gunung Salak Endah". Jakart a: LP3M STP Tri Sakti, Jurnal Ilmiah, Vol 5. No. 3 Maret 2001.

Che D, Veeck A, dan Veeck G. 2005. Sustaining Production and Strengthening the Agritourism Product: Linkages Among Michigan Agritourism Destinations, Agric and Human Value. 22 (2): 225-234.

David, Fred R. 2002. Manajemen Strategis. Prenhallindo. Jakarta.

Gill SS. 2009. Rural tourism Development Through Rural Cooperatives, Nat and Sci. 7(10): 1-9.

Herba. 2003. Karyasari. 7 Tahun Mengukir Dunia Herba. Karyasari. Jakarta.
Herlina, Liza. 2002. Analisis Strategi Pemasaran dan Pengembangan Usaha Kecil pada Pie Apple Pie Bogor. Skripsi. Jurusan Sosial Ekonomi Pertanian. Fakultas Pertanian. IPB. Bogor.

Jauch dan Glueck. 1993. Manajemen Strategis dan Kebijakan Perusahaan. Erlangga. Jakarta.

Kinnear, T.L. and Taylor. 1991. Marketing Research:An Applied Approach. Fourth Edition. Mc Graw Hill. USA.

Kotler, Philip. 1997. Manajemen Pemasaran. Analisis Perencanaan, Implementasi, dan Kontrol. Prenhallindo. Jakarta.

Laporan Pelatihan Pengelolaan Wisata Agro Tingkat Nasional. 2010. Proyek Koordinasi Penataan Pembagunan Pertanian. Biro Perencanaan dan Keuangan. Departemen Pertanian. Jakarta.

Pendit, Nyoman S. 1994. Ilmu Pariwisata Sebuah Pengantar Perdana. Jakarta: PT. Pradnya paramita.

Pearce dan Robinson. 1997. Manajemen Strategik, Formulasi, Implementasi dan Pengendalian. Jilid Satu. Binarupa Aksara. Jakarta.

Rangkuti, Freddy. 2002. Analisis SWOT:Teknik Membeda Kasus Bisnis. Gramedia Pustaka Utama. Jakarta.

Ridjal, Chairul. 1997. Identifikasi Unsurunsur Strategis dan Analisis Strategi dalam Pengembangan Usaha Agrowisata. (Studi Pada Pengembangan Taman Buah Mekarsari). Skripsi. Jurusan Sosial Ekonomi Pertanian. Fakultas Pertanian. IPB.Bogor.

Salah Wahab, 1975. Pengantar Ilmu Pariwisata. Bandung: Angkasa. 